\title{
The Ultimate Killer of New Retail: Data Empowerment
}

\author{
Yuting Chen
}

\author{
School of Economics and Management, Beijing Jiaotong University \\ * Corresponding author Email: cytcyt595947032@163.com
}

\begin{abstract}
With the rapid development of the Internet economy and the rapid change of information technology, people's needs are also undergoing obvious and rapid upgrades. Both the physical store model and the pure online shopping model can no longer fully meet the needs of consumers. In this environment, a new "unbounded" and "smart" retail mode, which combines online and offline with modern intelligent logistics, is born at the core of satisfying diversified demands of consumers in various scenes. The upgrading of retail formats and the improvement of operational efficiency are inseparable from the data empowerment of new information technology. This paper explores the important role of big data technology in reconstructing the relationship between people, goods and stores, and explains in detail the means and measures of the retail industry driven by big data to improve the efficiency of consumer operators, supply chain and channel, so as to provide ideas for the next development of the new retail model driven by big data.
\end{abstract}

Keywords: The new retail, Unbounded retail, Data enablement, Digital transformation.

\section{FIRST LEVEL HEADING (HEAD 1)}

The body text starts with a standard first-level heading like INTRODUCTION or any other heading suitable to the content and context. First level headings are in all caps. Copy the content and replace it for other first-level headings in remaining text. Reference citations should be within square bracket [1]. Headings should always be followed by text.

\section{BIG DATA EMPOWERMENT CAN MEET BUSINESS' NEEDS}

\subsection{More Accurate Consumer Portraits}

The traditional user portrait generally refers to the basic information of typical users extracted by the product departments and managers of enterprises, and the information is analyzed qualitatively and summarized abstractly, so as to analyze the consumption demand of users and the reasons for the demand, think about the value of products from the perspective of users, and speculate the possible scenarios for users to use products. In the digital era, we need more accurate consumer portraits. The application of big data technology can help the retail industry to create more abundant, three-dimensional and dynamic holographic consumer portraits, which are specifically manifested in the visualization of user data information and systematic labels for user behavior.

The first is the visualization of user information data, including user behavior data and consumption trajectory. As shown in Figure 1, when we do online shopping, we will go through a series of links, during which rich information will be generated. Businesses can grasp information through technical means and conduct further analysis, which is the online user behavior data; similarly, consumers have to go through many processes, and then generate offline user behavior data, such as brand preference, dynamic line analysis, hot zone analysis, payment method preference and so on. 


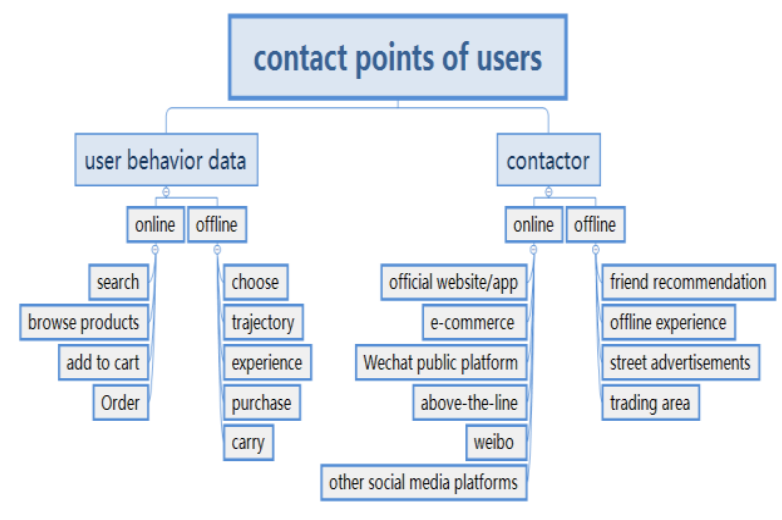

Figure 1.Contact points of users in consumer portraits.

The second is the systematic label of user behavior. User behavior tags can be divided into four categories: population, society, interest preference and cognition. As shown in Figure 2, each of the four attributes contains many different tag information.

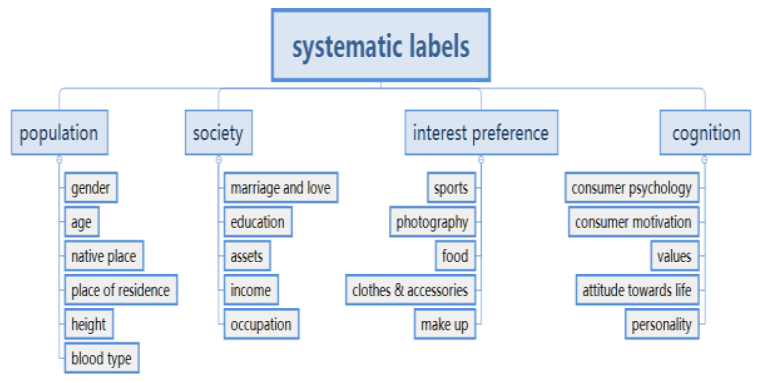

Figure 2.Systematic labels in consumer portraits.

With the help of Internet big data, all the data generated by customers in the process of consumption will be collected, and the ability of big data integration will be used to further analyze and sort out the data. Therefore, enterprises have more accurate quantitative indicators when making business decisions, which is convenient for enterprises to conduct customer group analysis and brand adjustment, accurately depict consumers, provide customers with more palatable products, create more suitable marketing activities, and improve customers' consumption experience. For example, Xidan Joy City stores deployed nearly 400 WiFi hotspots and nearly 3000 ibeacon devices in an all-round way to monitor and collect customer behavior and consumption trajectory in real-time. In only one year, it sorted out 50 billion consumption data of 50 million customers. According to the 292 labels set by the system for customers, it divided six core customer groups. In the overall decline of the physical retail environment, it broke through the encirclement, realized the growth against the trend, and completed the value chain remodeling.

\subsection{Increase the Joint Rate}

The joint rate was originally just an indicator of sales in the apparel industry, and its calculation formula is as follows:

Joint rate $=$ total sales quantity $\div$ sales receipt quantity

Now the joint ratio has been upgraded to an important reference for measuring sales results and index completion. When the calculated value is lower than 1.3, it indicates that there are serious problems in the sales situation of stores. At the same time, the joint rate is also an effective means to improve the unit price of shop customers. In the digital age, it is completely impossible to rely solely on salespersons. Internet companies are more likely to use big data tools to achieve their goals. For example, if a customer places an iPad on Taobao, the recommended products on Taobao's home page in the next few days will surely have a high density of iPad cases, computer bags and other related products. With the accurate recommendation of big data, powerful e-commerce giants like Alibaba will join in artificial intelligence, automatically generate advertising images on Web pages, and improve the connection rate of consumers when shopping in multiple ways, so as to create greater value for retail.

\subsection{Optimize the Membership System}

For the whole retail industry, the cost of acquiring new customers is getting higher and higher. Many businesses attract a large number of traffic in a short time by means of promotion and discount. However, these new users are only driven by profits, and the marketing cost will continue to rise, but the effect will continue to weaken. In this case, it is an important breakthrough to enable users to have continuous purchasing behavior and tap the lifetime value of customers. This path is called improving the "repurchase rate". Mr. Liu run, an expert in Internet transformation, calls it "the ultimate killer of new retail".

Membership system is an effective means to improve the repurchase rate. Compared with ordinary customers, members have incomparable advantages and values in cost control, marketing effect, brand identity and so on. In the wave of digital transformation, the membership system has also completed the structural optimization due to the empowerment of big data. Compared with the traditional membership system, the membership system under the new retail mode has a brand-new operation method, such as online point accumulation points to collect coupons, offline enjoy discount benefits; online access to service information to make an appointment, offline experience consumption; online view of preferential introduction, 
offline transaction collection, etc. In addition to the combination of ondabline and offline, the whole process of tracking customer behavior through user data, continuous service and personalized recommendation are also the characteristics of membership system promoted by big data. Taking a medical beauty agency in Beijing as an example, the organization will establish a skin diagnosis and treatment file bag for its members, record the member's skin condition, the process of diagnosis and treatment each time, the products and operation technicians used, and provide personalized management projects for customers. In addition, the system will carry on the integral according to the customer's consumption situation, and display the preferential price when the customer arrives at the store to pay. It is precisely because of its membership system based on the results of big data processing that the satisfaction of customer survey in each quarter is excellent. It has the incomparable customer loyalty of competitors in the same industry, and the word-of-mouth effect of old customers leading new customers.

\subsection{Make Accurate Product Selection with Big Data}

For retailers, it is not flashy advertising, clever marketing and deep discounts that really move consumers and turn them into business value, but the product itself. To come up with the best products to stimulate consumers' desire to buy, selection is the most important first step in the long march. A successful selection can make the process of retail value creation twice with half the effort. On the contrary, a failed selection may also make retail enterprises unable to survive and withdraw from the competitive market. The traditional distribution mode is gradually eliminated in the era of rapid development. In order to ensure the performance and development of stores, accurate product selection is an important shortcut and a very good breakthrough.

Similar to accurately depicting consumer portraits, new retail uses big data technology to achieve the purpose of accurate selection. Xiaomi and Amazon, for example, use big data to accurately select products. By collecting and analyzing massive data, they find the products with the strongest demand of consumers, and build them into highly sought after "explosive products". They can not only bring huge sales, but also reduce supply chain costs, improve conversion rate and greatly improve profitability. In addition to boosting the implementation of "explosive products", accurate selection also reflects regional and seasonal differences in product supply. According to the information reflected by the big data of commodities, retailers arrange the selection of products in different regions or seasons, accurately distribute goods, and make unified scheduling, so as to improve the efficiency of resource utilization and avoid meaningless waste. In addition, through the big data analysis of the commodity warehouse, retailers can also find the gaps in the market in time. After a series of calculation and market feasibility investigation, they can timely launch products to fill the market gap and seize the market opportunity.

\subsection{Optimize the Supply Chain and Supply Intelligently}

The traditional retail supply chain is based on the business as the source, providing products or services to the final consumers, "what the merchants sell, the consumers buy what". In the digital era, the supply chain has also appeared a new form under the influence of big data: reversible supply chain. The specific process is as follows: 1) brand companies collect preference demand data from consumers; 2) data integration is carried out in the data background; 3) data results drive the factory to carry out personalized customized production; 4) data driven more efficient logistics; 5) commodity delivery to consumers. It subverts the traditional mode of information flow from businesses to consumers. Starting from consumer demand, it forces the planning of the whole process of production and sales. Based on consumer data, it provides personalized customized services for customers, so as to reverse promote the supply chain and make the whole process more efficient.

The reversible supply chain also has a huge advantage, that is, it can forecast the latest demand according to the collected consumer data, and use the result analysis to carry out product research and development. After that, big data is used to further identify customers, complete the prediction of order quantity and the planning of supply quantity, so as to carry out rapid production and realize the real intelligent supply. Moreover, accurate supply of product sales through big data can effectively solve the problem of inventory turnover, clear inventory, and make enterprises no longer trapped in the dilemma of unsalable.

\section{ENABLING BIG DATA CAN MEET THE NEEDS OF CONSUMERS}

Nowadays, more and more operators realize the importance of consumers, and many enterprises take "customer first" as the purpose. From the perspective of meeting consumers, this section will analyze how big data can enable new retail, improve the efficiency of consumers and operators, and create greater value. 


\subsection{Integration of Online Efficiency and Offline Experience}

"Shop around" has been a shopping principle for centuries. This requires customers to compare the information flow provided by different businesses, choose their favorite one for consumption. However, the acquisition of information flow in traditional brick-and-mortar stores requires consumers to invest a lot of time and energy. In order to compare the price of a shirt, consumers may have to travel across the city to compare prices at several shopping malls in order to choose the best one. Offline retail is inefficient in obtaining information flow. In contrast, the majority of online sales platforms represented by Taobao directly address this drawback of physical retail, attracting a large number of consumers with "fast speed, full range of goods and cheap price", and greatly improving the efficiency of information flow. Efficiency is the biggest advantage and common feature of online retail. However, Internet shopping has always been unable to beat physical shopping, which is experience. When consumers browse Taobao, Amazon and jd.com, they can only know what they want to buy through the pictures, product information and the evaluation of the buyers. When shopping in shopping centers and supermarkets, they can feel the actual characteristics of the products in person without fear of being blinded by false information. This reflects the three-dimensional and multi sensory advantages of offline retail. How to combine offline advantages with online advantages? The answer from the new retail model is "data empowerment".

Xiaomi may be a pioneer who has the courage to realize the "combination of online efficiency and offline experience". In 2015, the first Mi Home experience store was opened in Beijing. "Experience only without selling goods" is its biggest feature. Consumers can directly access a variety of products in the Xiaomi ecological chain, from cheap signing pens to high-end and expensive balance cars. What's more, the most attractive point is that the price of Xiaomi's products is completely consistent with the online price, and consumers can immediately place orders online. This is to make up for the vacancy and deficiency of online retail by using the experience of offline retail. The efficiency of online retail is reflected in the self-service shopping screen in the store. After consumers get the most desirable products carefully selected by themselves, they can directly scan the QR code to complete the payment process without going through the checkout counter. process. Moreover, the Xiaomi Home Experience Store can predict sales and effectively reduce inventory based on the data provided by the Xiaomi online mall. This is how offline retail uses the efficiency of online information flow to help itself.

\subsection{Scenes that Exist Anytime, Anywhere}

In the past, retail and our life were independent. There was a clear boundary between retail scene and life scene. If you want to buy a book, you can only go to the bookstore. If you want to buy a washing machine, you will often choose the electric city. The type of shop is fixed, and the channel is also fixed: go shopping on weekends and drink coffee at leisure in the afternoon. Although demand may arise at any time, the time point we need to get to our daily life is fixed. However, the consolidation of this consumption scenario does not match our growing diverse new needs. Therefore, in the era of mobile Internet, the application of data makes it possible to break the time and space boundaries of consumption scenarios. It connects all the things we need together, making the scene closer to our life, more emotional and more temperature.

Data empowerment first helps to eliminate the strict spatial boundaries of consumption scenarios. Our shopping behavior does not need to be restricted by specific places. It can happen anywhere: social media, e-commerce platforms, physical stores, QR codes of street advertisements, unmanned retail containers, etc. as long as there is demand, data will be generated. Through data analysis, retail scenes are integrated into life scenes, retail scenes are ubiquitous, and the role of flow center is infinitely weakened. Secondly, data empowerment helps eliminate the strict time constraints in consumption scenarios. In the past, we had to go through a series of time-consuming and laborious processes such as search, selection, consultation and bargaining. Now, with the help of data, the occurrence of retail actions becomes more flexible and diverse. Our expression and action may be quickly identified and captured by information technology, and integrated into consumer behavior data, and then trigger orders to meet our needs of traveling every minute. In the era of Internet mobile, the fragmentation trend of consumption scene is more and more obvious, consumer demand is more flexible and changeable, and retail behavior is no longer unchanged. Through data analysis, retail will digitize consumers, build ubiquitous consumption scenes, and gradually integrate into people's lives.

\subsection{Integration of Online Span and Offline Accessibility}

Shopping in supermarkets, shopping in shopping malls, and choosing fruits and vegetables in vegetable markets are all characterized by "consumers looking for commodities". There is a big problem in this form of retail, which is limited by the space distance. Whether it is the Chinese people's habit of buying and using in the community supermarket under their own buildings, or the Americans' habit of driving to the far away super market to purchase in large quantities, the radius of 
consumer activities is limited. Since the 1990s, the rise of Internet shopping has effectively solved this problem. The span of logistics seems to make the earth very small. Goods all over the world can actively find consumers through e-commerce platforms. Efficient logistics has replaced the inefficient flow of people, and shopping has become accessible. However, the shortening of space distance is at the cost of increasing time investment. When consumers choose to shop online, they have to choose to increase their waiting time to get more distant goods. Not all categories of goods are worth the huge time cost of consumers to obtain, and not all consumer demand can withstand the waiting time. For example, if you find that you have run out of salt when cooking, you will choose to buy a bag of imported high-grade salt on Tmall or buy a bag of it in the small supermarket downstairs for emergency. The answer is self-evident. This shows that offline retailing is not completely defeated by online retailing. It has the advantage that online retailing can't surpass. It suppresses the "near" of offline retail space with the "fast" in time. So, how do consumers want to get a "fast and close" shopping experience? The answer given by the new retail model is "data empowerment".

Take Alibaba as an example, every year's double 11 shopping carnival is the most anticipated and exciting moment for consumers. Consumers will start to add the products they want to the shopping cart several weeks or even months in advance. The extensive promotion and publicity on Taobao's page will go online early in advance to guide everyone to "join the shopping cart". In fact, this is the data collection stage of Alibaba. It collects a lot of information about the products added to the shopping cart of consumers. Even during the "double 11" period, the maximum number of goods in the shopping cart will increase. According to the data information of shopping cart goods collected, Alibaba will forecast the consumption demand quantity and regional distribution, and use powerful data system to enable logistics and warehousing. According to the prediction results, before the arrival of the double 11 , the goods that consumers want to buy will be packed in advance and sent to the warehouse in the demand area. As soon as the time comes, the goods will wait for us to place an order and then deliver them to us as soon as possible. Big data enables retail to realize the integration of online span and offline accessibility. Consumers can not only enjoy the "fast" in time, but also enjoy the "proximity" in space. Data empowerment greatly improves the channel efficiency.

\subsection{Integration of Online Payment Convenience and Offline Payment Credibility}

In addition to the efficiency of information flow and the span of logistics, online retail also has a very important feature and advantage, that is, the convenience of capital flow. In the past, when we were shopping in the supermarket, we needed to prepare a certain amount of paper money or carry a bank card. It was troublesome to carry, and there was a risk of losing it carelessly. Sometimes, we would encounter the situation that the supermarket could not change, which was very inconvenient. The emergence and popularization of mobile payment solves this problem well, and the appearance of two-dimensional code of collection and payment greatly improves the convenience and efficiency of transaction. However, we often say "no pay no goods". In online shopping, due to the limitation of time and space, we can not realize the synchronous occurrence of capital flow and logistics, and there is a lack of trust between consumers and businesses. In particular, consumers are more willing to swipe their cards face-to-face when buying such high-value commodities as houses, cars, jewelry and diamond rings. In this dimension, the credibility of offline payment is higher than that of online payment. Data empowerment can integrate online convenience with offline credibility.

The "sesame credit" module in Alipay is a good example of using data to empower Internet capital flows. Sesame credit data collection is carried out according to the five dimensions of identity characteristics, behavior preference, interpersonal relationship, credit history and performance ability. The credit score of each evaluation dimension is calculated according to the weight model, and finally four credit grades of "poor, medium, good and excellent" are generated. Users can enjoy different services according to their own credit rating. For example, when traveling abroad, when renting mobile wifi on the Feizhu platform, customers with sesame credit over 650 points can enjoy the credit deposit free service. They only need to pay the rent without deposit. This is to improve the credibility of consumers by using data. Taobao's Alipay service is the "intermediate guarantee" of transactions when buyers and sellers conduct transactions. Consumers' money will not enter the merchant account before consumers receive the merchandise confirmation. This is to use data to improve consumers' trust in businesses and retail platforms. Thus, enabling the capital flow of the Internet with data can effectively integrate the convenience of online payment with the credibility of offline payment, and promote the smooth and high-quality operation of retail.

\section{CONCLUSION}

At present, the traditional retail industry is facing unprecedented challenges. For physical retail, the main problems are low storage efficiency, high labor costs, continuous decline in passenger flow and slow commodity update speed; for pure e-commerce retail, the main problems are that the platform tends to be 
saturated, unable to overcome the strong offline passenger flow and high logistics costs. According to the above analysis, traditional retailers can use data enabling means for transformation: big data insight into consumers, precision marketing; innovative business model, online and offline linkage; cross channel integration of information, optimize the supply chain, and comprehensively promote the upgrading of retail formats and the improvement of operational efficiency.

\section{REFERENCES}

[1] Issa,Byers,Dakshanamurthy. Big data: the next frontier for innovation in therapeutics and healthcare[J]. Expert Review of Clinical Pharmacology,2014,7(3).

[2] Manyika J, Chui M, Brown B, et al. Big data: the next frontier for innovation, competition, and productivity.Mc Kinsey Global Institute, 2011

[3] Cukier K. Data, data everywhere. Economist, 2010, 394: $3-16$

[4] Lohr S. The age of big data. New York Times, 2012, 11

[5] Labrinidis A, Jagadish $\mathrm{H}$ V. Challenges and opportunities with big data. Proc VLDB Endowment, 2012, 5: 2032-2033

[6] Rigby D. The future of shopping[J]. Harvard Busi-ness Review, 2011( 12) : 64-75

[7] Wang Baoyi. The essence, causes and practice trend of "new retail", China circulation economy, 2017, 31 (07): 3-11

[8] Zheng Guihua, Li Huli. Research on the problems and Countermeasures in the process of transformation of real retail industry into "new retail" [J]. Economic Forum, 2017 (05): 72-75
[9] Zhao Shumei, Xu Xiaohong. The meaning, mode and development path of "new retail" [J]. China circulation economy, 2017,31 (05): 12-20

[10] Du Ruiyun, Jiang Kan. New retail: connotation, development motivation and key issues [J]. Price theory and practice, 2017 (02): 139-141

[11] Jiang Yaping, Ren Xiaoyun. From the perspective of the "wheel of retail" theory, the causes and development strategies of new retail $[\mathrm{J}]$. Economic Forum, 2017 (01): 99-101

[12] Tian Jingjing, Yang Haili, Yang jian'an.new retail: motivation, characteristics, status quo and trend $[\mathrm{J}]$. Journal of Zhengzhou Institute of aeronautical industry management, 2018,36 (03): 57-64

[13] Pan Jianlin. Literature review of new retail Theory: also on four dimensional business model [J]. Business economics research, 2019, (05): 9-11

[14] Guo Peng. Research on customer perceived value under the new retail mode [D]. Hebei University of science and technology, 2019

[15] Zhang Zijian, Xue Chuanli. Research on the optimization of retail enterprise supply chain under Omni channel mode [J]. Industrial economy forum, 2016,03 (04): 468-476

[16] Qi Yongzhi, Zhang Mengxia. Channel evolution of retail enterprises driven by solomo consumption: Omni channel retail $[\mathrm{J}]$. Economic and management research, 2015,36 (07): 137-144

[17] $\mathrm{Xu}$ Huizhen. Innovation of traditional retail business model under Omni channel [J]. Business economics research, 2015, (12): 20-21

[18] Li Fei. Omni channel marketing: a new strategy [J]. Tsinghua management review, 2015, (z1): 32-39 